\title{
ENTRE LA CRUZ Y LA ESPADA: EL DERECHO DEL ACCESO A LA JUSTICIA Y LAS INMUNIDADES DE JURISDICCIÓN DE LOS ESTADOS
}

\section{BETWEEN THE CROSS AND THE SWORD: THE RIGHT TO ACCESS TO JUSTICE AND THE IMMUNITIES OF JURISDICTION OF STATES}

\author{
Martha Lucia Olivar Gimenez \\ Mestre y doctora por la Université Robert Schuman - Strasbourg. Pos-doctora por la \\ Universidad de Nottinghan. Profesora asociada de la Universidade Federal do Rio Grande \\ do Sul -UFRG. E- mail: martha.olivar@gmail.com
}

Valesca Raizer Borges Moschen

Doctora por la Universidad de Barcelona. Profesora asociada de la Universidade Federal do Espírito Santo - UFES. Coordinadora de la línea de investigación sobre Proceso Civil Internacional del Núcleo de Estudios en Proceso y Tratamiento de Conflictos - NEAPI. E-mail: raizervalesca@gmail.com

Paula Soares Campeão

Maestranda del Programa del Master en Derecho Procesal de la Universidade Federal do Espírito Santo - UFES. Miembro del Núcleo de Estudios em Proceso y Tratamiento de Conflictos - NEAPI. E-mail: paulacampeao@hotmail.com

Convidados

No habrá nunca una puerta. Estás adentro
y el alcázar abarca el universo
y no tiene ni anverso ni reverso
ni externo muro ni secreto centro ${ }^{1}$.

RESUMEN: Las inmunidades de Estado extranjero hacen parte de una categoría de asuntos que impone la convergencia entre el Derecho Procesal, el Internacional Privado y el Público. La movilidad de los factores de producción (capital y trabajo), la masiva circulación de las personas físicas y jurídicas y de las mercadorías, consagradas por la mundialización económica, fomentó la transnacionalización de las relaciones sociales eeconómicas y,con esas, el aumento de la conflictualidad internacional. De otro lado, la disminución de la centralidad del Estado en el orden jurídico contemporáneo, con la asunción de la persona humana como eje central del derecho, generó la necesidad del análisis de la dicotomía entre la efectividad de derecho y garantíasversus la aplicación del principio de excepción de la sumisión por un Estado a la jurisdicción de otro Estado nacional. A partir de una metodología "jurisdiagnóstica", el presente artículotiene como objetivo trabajar el complejo equilibrio entre la inmunidad de jurisdicción de los Estados extranjeros y la trasnacionalización del acceso a la justicia.

${ }^{1}$ BORGES, Jorge Luis, Laberinto, Obras Completas.2.ed., Barcelona:Emecé, 1999.

Revista de Direito Brasileira | São Paulo, SP | v. 19 | n. 8 | p. 155 - 169 |Jan./Abr. 2018 
Palabras-llaves: Inmunidad de Jurisdicción. Acceso a la Justicia.Derecho Procesal Civil Internacional. Convención de las Naciones Unidas sobre las Inmunidades de Estados y sus bienes.

ABSTRACT: The immunities of a foreign State are part of a category of matters that imposes the convergence between Procedural Law, Private International and Public. The mobility of the factors of production (capital and labor), the massive circulation of physical and legal persons and of the merchants, consecrated by economic globalization, fostered the transnationalization of social and economic relations and, with them, the increase in the international conflictuality. On the other hand, the reduction of the centrality of the State in the contemporary legal order, with the assumption of the human person as the central axis of the law, generated the need for the analysis of the dichotomy between the effectiveness of rights and guarantees versus the application of the principle of exception of the submission by a State to the jurisdiction of another national State. Based on a "jurisdiagnostic" methodology, this article aims to work the complex balance between the immunity of jurisdiction of foreign States and the transnationalization of access to justice.

Keywords: Immunity of Jurisdiction. Access to Justice. International Civil Procedure Law. United Nations Convention on the Immunities of States and their property.

SUMÁRIO: Introducción. 1. La cuarta onda del acceso a la justicia: Su transnacionalización. 1.1. La consagración del acceso a la justicia como un derecho fundamental. 2. Los andamios de la inmunidades de jurisdicción: Límites y posibilidades. 2.1. Mitigación de la inmunidad de jurisdicción en Brasil a la luz de la Convención de las Naciones Unidas de 2004. 3.Consideraciones finales: La dictadura brasileña en los tribunales italianos ¿nueva dimensión de la inmunidad? Conclusión. Referencias.

\section{INTRODUCCIÓN}

Las inmunidades de Estado extranjero hacen parte de una categoría de asuntos en que el Derecho Internacional Público y el Derecho Internacional Privado se relacionan estrechamente.A tal interacción se suma la necesidad del diálogo de ambas disciplinas con el derecho procesal,una vez quela gran mayoría de países, entre los que se encuentra Brasil, deja la solución de las controversias que interviene un Estado extranjero, en manos de susistema judiciario nacional. ${ }^{2} \mathrm{La}$ práctica de los tribunales nacionales e, incluso internacionales, en la materia, comprueban la interdependencia, la complementariedad y la ayuda mutua entre estos tres ramos del derecho.

Para el derecho internacional público,la inmunidad de jurisdicción secaracteriza como una instituciónjurídica circunscrita al principiode igualdad soberana de los Estados ${ }^{3}$, que concede a un Estado extranjero la prerrogativa de no someterse al judiciario en otro Estado nacional. Tal institución,al estar vinculada a la soberanía estatal,muchas veces "actúa en detrimento de las expectativas de quien ejerce la acción para lograr la tutela judicial efectiva de sus derechos ${ }^{4}$ ".

Desde el prisma del derecho internacional privado, la inmunidad se insiere en el campo del análisis de los límites del ejercicio de lajurisdicción del Estado, y su enfoque se direcciona a

\footnotetext{
2 JIMENEZ, Martha L, MOSCHEN, Valesca RB, Las inmunidades de Estado Extranjero en la Pauta del Judiciario Brasileño: Avances y Desafios, Civil ProcedureReview, v.4, n.3: 99-121, sep-dec., 2013.

${ }^{3}$ FINKE, Jasper Sovereign Immunity: Rule. Comity or Something else? European Journal of International Law, Vol.21, n.4, 853-881,esp.p.855.

${ }^{4}$ BONET, Jordi Perez, La inmunidad de jurisdicción del Estado en la jurisprudencia del Tribunal Europeo de Derechos Humanos: la relación laboral al servicio de oficinas diplomáticas. FORNER, Delaygua, Joaquim, BEILFUSS, Cristina Gonzales y VIÑAS, Ramón Farré (coord.) Entre Bruselas y la Haya Estudios sobre la unificación internacional y regional del Derecho internacional privado, LiberAmicorum Alegría Borras, Barcelona; marcial Pons, 2013, p.225-239. esp. 235.
}

Revista de Direito Brasileira | São Paulo, SP | v. 19 | n. 8 | p. 155 - 169 |Jan./Abr. 2018 
la protección de la persona física y/o jurídica víctima de un ilícito acometido por otro Estado nacional, que serán partes de un conflicto con, al menos un elemento de extranjería, sea o en su procesamiento, o en la ejecución de una eventual decisión.

Finalmente, para el derecho procesal,que se quedó encapsulado en una esfera eminentemente nacional, por diferentes justificativas, entre las cuales por la comprensión histórica deque,al reglamentar el ejercicio de la jurisdicción, era parte integrante del campo jurídico con amplia identidad nacional.La inmunidad de jurisdicción se ve como un incidente procesal $^{5}$, que inhibe el ejercicio de la jurisdicción por parte de un Estado nacional, no obstante gozar este Estado de competencia para su actuación.

En base ala preocupación creciente conla promoción y la protección de la persona humanay con ella, la ampliacióndel concepto de jurisdicción, no más como la aplicación concreta de la voluntad de la ley, pero como un instrumento de pacificación social, destinado a atender a la tutela de derechos y personas ${ }^{6}$, al diálogo tridimensional se impone la necesidad del análisis por la búsqueda de la solución adecuada a la dicotomía entre : el acceso a la justicia y la efectividad de derecho y garantías de las personas versus la aplicación del principio de excepción de la sumisión de un Estado a la jurisdicción de otro Estado nacional.

Inserida en esta perspectiva de aproximación interjurisdiccional, la investigación se propone a perquirir la flexibilización de la técnica de inmunidad de jurisdicción, para el fin de alzar vectores fundamentales de acceso a la justicia en el proceso constitucional internacional. De esta forma, el presente artículo, a partir de una metodología“jurisdiagnóstica”, comprendida como "un abordaje preliminar de un problema jurídico que resalta características, percepciones e descripciones, sin preocupar con susraíces explicativas "'busca contribuir para el estudio del actual panorama dialéctico en la relación a los límites y la extensión de la inmunidad de jurisdicción del Estado y el principio del acceso a la justicia.Dialéctica aquí intitulada "entre la cruz y la espalda".

\section{LA CUARTA ONDA DEL ACCESO A LA JUSTICIA: SU TRANSNACIONALIZACIÓN}

Las ondas renovadoras ${ }^{8}$ de acceso a la justiciadefendidas y proclamadas por los profesores Mauro Cappelletti e Bryant Garth, desembocaron en un movimiento científico de actualización de la propia concepción de justicia. En este contexto, la caracterización neutral y normativa, perdió relevo frente a la necesidad de una cualificación de justicia en cuanto instrumento de concretad de derechos, a partir de un real y efectivo acceso.

La evolución propuesta por los autores, concebía el acceso a la justicia a partir de tres ondas, una primera, proponiendo el acceso a la justicia a luz de la disminución de su costo y obstáculos económicos. Luego, una segunda, comprendiendo la dimensión colectiva del acceso a la justicia y la consecuente necesidades de proclamación de una tutela coherente a la protección de derechos difusos y colectivos. Y, finalmente, una tercera, donde se exalte las formas

\footnotetext{
${ }^{5}$ MADRUGA FILHO, Antenor, A renúncia à imunidade de jurisdição pelo estado brasileiro e o novo direito de imunidade de jurisdição. Rio de Janeiro:Renovar, 2003, p.226.

${ }^{6}$ Para Fredier Didier Jr lajurisdición es "uma função atribuída a um terceiro para realizar o direito de modo imperativo e criativo reconhecendo /efetivando/protegendo situações jurídicas". DIDIER, Fredie Jr, Curso de Direito Processual Civil, 17ed., Salvador:Ed Jus Podivm, 2015, p.153.

${ }^{7}$ DIAS, Maria Tereza Fonseca; GUSTIN, Miracy Barbosa de Sousa. (Re)Pensando a pesquisa jurídica: teoria e prática. 4. ed. Belo Horizonte: Del Rey, 2013. p. 27.

${ }^{8}$ Termo consagrado por los profesores Mario Cappelletti e Bryant Garth, que indican la necesidad de un debate continuo sobre el desarrollo del análisis del principio de acceso a la justicia y de su relación con "el tipo" de justicia que se pretende resultar. CAPPELLETTI, Mauro (ed) Access to Justice and the Welfare State.Forenze: BadiaFiesola, 1981, pp 5-55.
} 
adecuadas de solución de conflictos, incorporando dentro de la búsqueda por la proclamación de justicia, los métodos de auto y hetero composición.

En el contexto de una sociedad globalizada, el acceso a la justicia pasa a ser requerido como un derecho fundamental a la persona en su propagación en el espacio". De esta forma, "la efectividad del acceso para todos al sistema legal, a sus derecho, libertades y beneficios; acceso a los instrumentos, incluyendo los tribunales, que puedan valer aquellos derechos, libertades y beneficios de forma significativa y efectiva ${ }^{10}$ " es un derecho fundamental y también debe ser observado en un litigio entre un particular y un Estado extranjero, en un foro nacional diverso del estatal.

\subsection{La Consagración del Acceso a la Justicia como un Derecho Fundamental}

El movimiento de universalización de los derechos humanos nace como propulsor de un padrón de convergencia valorativa en el plano normativo y como terreno fértil para legitimar la confianza mutua de las relaciones internacionales.Se parte del supuesto de que la comunidad internacional comparte un mínimo universalizable de valores básicos ${ }^{11}$. Tales valores constituyen un tema de legítimo interés internacional y encuentran cimiento en el ideal de derechos humanos, que trasciende y extrapola el dominio reservado del Estado nacional ${ }^{12}$.

De esta forma, la primacía de la dignidad de la persona humana se impone como núcleo básico e informador de la práctica jurídica de conexión mundial, debiendo ser adoptada como parámetro de valoración orientador de la interpretación y comprensión del sistema de valores fundamentales, en el ámbito procesal internacional.

En el ámbito del derecho internacional, la garantía de acceso a un proceso justo y equitativo pasó a representar una preocupación recurrente en los instrumentos internacionales de protección y promoción de los derechos fundamentales en el transcurso del tiempo. Estos instrumentos, influencian en la actualidad, la consagración de tal garantía a nivel nacional y condicionan la actuación de los tribunales nacionales en la determinación de sus propios límites.

En la Declaración Americana de los Derechos y Deberes del Hombre, aprobada en la 9a Conferencia Internacional Americana, celebrada en Bogotá en 1948, en su artículo 18, ya se delineaba la comprensión del derecho fundamental a la justicia como aquel derecho de recurrir a los tribunales para hacer respetar sus derechos. Su ejercicio debería contar, "como un proceso caracterizado como simple y breve, mediante el cual la justicia la proteja contra actos de autoridad que violen, en su perjuicio, cualquiera de los derechos fundamentales consagrados constitucionalmente."13

En el mismo sentido, pero en el ámbito universal, la Declaración Universal de los Derechos Humanos de la Organización de las Naciones Unidas, de 10 de diciembre de 1948,

\footnotetext{
${ }^{9}$ LOPES, Inez, A família transacional e a cooperação jurídica internacional. Revista dos Tribunais. Caderno Especial. Cooperação Jurídica Internacional. vol I, Abril/2018, pp. 83-113.

${ }^{10}$ CAPPELLETTI,Mauro (ed), Access to Justice and the Welfare State. op. cit. p.24.

${ }^{11} \mathrm{La}$ asunción de valores universales muchas veces encuentran sus límites en el proprio contexto global,conforme la percepción Vladmir Oliveira da Silveira, muchas veces "la modernidad y la consecuente sociedad tecnológica , caracterizada por el racionalismo científico y por el productivismo coloquen en jeque los principios del humanismo". SILVEIRA, V. O.; CASTRALLI, R. B. . A dimensão ecológica dos direitos humanos e a redefinição do valor do trabalho humano. REVISTA THESIS JURIS, v. 04, 2015. pp. 61-86.

${ }^{12}$ Para Peter Haberle, en la actualidad, los Estados constitucionales encuentran su identidad también en el derecho internacional. HABERLE, Peter, Estado Constitucional Cooperativo, Rio de Janeiro:Renovar, 2007, p.59. Este hecho implica en la promoción necesaria de la solidaridad y de la disposición para la cooperación internacional, incluso a nivel jurídico privado. MOSCHEN, Valesca Raizer Borges; MARCELLINO, H. Estado Constitucional Cooperativo e a codificação do direito internacional privado: apontamentos sobre o Judgment Project da Conferência da Haia de direito internacional privado. Argumentum, v. 18, 2017. pp. 291-319.

${ }^{13}$ Disponible en: <https://www.cidh.oas.org/basicos/portugues/b.declaracao_americana.htm>Acceso al 16 de junio de 2018.
} 
incluye en el concepto de proceso justo y justo, según se desprende de su artículo 10, independencia e imparcialidad del tribunal. ${ }^{14}$

Desde la perspectiva de la Organización de os Estados Americanos, en el 22 de noviembre de 1969, en la Conferencia Especializada Interamericana sobre Derechos Humanos en San José, Costa Rica, finalmente se consagra el derecho al acceso a la justicia como derecho fundamental en su artículo 8,

"toda persona tiene derecho a ser oída, con las debidas garantías y dentro de un plazo razonable, por un juez o tribunal competente, independiente e imparcial, establecido anteriormente por ley, en el escrutado de cualquier acusación penal formulada contra ella, o para que se determinen sus derechos $\mathrm{u}$ obligaciones de naturaleza civil, laboral, fiscal o de cualquier otra naturaleza"15.

La búsqueda por la ciudadanía procesal a ser atingida,"en concreto, con efectividad y seguridad jurídica, como valores fundamentales analizados en una perspectiva de complementariedad y en una perspectiva dinámica"16, es fruto de la nueva teoría procesal consagrada en los instrumentos internacionales, que, como visto, incorporaran los valores y de las garantías procesales en cuanto derechos fundamentales. ${ }^{17}$

La nueva perspectiva principiológica posee el condón de alzar los principios jurídicos a la condición de eslabón normativo en el proceso de armonización jurídica internacional.A partir de la perspectiva de constitucionalización del proceso, surge la necesidad de mitigar la tradicional concepción que relaciona jurisdicción, soberanía y territorio del Estado-nación, para el fin de reconocer y asegurar la nueva dimensión de la justicia civil ${ }^{18}$.

El principio del acceso a la justicia, sobre todo en su acepción que trasciende la esfera de localidad, presupone la noción de proceso justo y equitativo, que se materializa por medio de la observancia de los vectores del debido proceso legal, efectividad, isonomía, contradicción, amplia defensa y amplia de su duración razonable ${ }^{19}$.Se trata del reconocimiento y de la consagración de una dimensión del proceso que se propone a alzar valores fundamentales procesales ya promover una efectiva armonización jurídica en el escenario de la constitucionalización del derecho procesal $^{20}$.

En ese contexto, se propone el repensar de las técnicas procesales tradicionales, en busca de mecanismos que se corresponden con la nueva perspectiva que orienta las relaciones procesales internacionales. La búsqueda de la armonización jurídica exige la flexibilización de técnicas tradicionalmente concebidas en el proceso civil para el fin de promover el efectivo acceso a la justicia.

\footnotetext{
${ }^{14}$ Art. X. Todo ser humano tem direito, em plena igualdade, a uma justa e pública audiência por parte de um tribunal independente e imparcial, para decidir sobre seus direitos e deveres ou do fundamento de qualquer acusação criminal contra ele. Disponible en: 〈http://www.onu.org.br/img/2014/09/DUDH.pdf > Acceso al 15 jun. 2018.

${ }^{15}$ En el plano regional americano, llaman atención los profesores Flavia Hill e Humberto Dalla Bernardina sobre la importancia del Pacto de San José de Costa Rica, como un marco en la garantía del acceso a una orden jurídica justa y en la consagración de los principios de garantías procesales, HILL, Flávia e PINHO, Humberto D.B., "A Nova Fronteira do Acesso à Justiça: A Jurisdição Transnacional e os Instrumentos de Cooperação Internacional no CPC/2015 Revista Eletrônica de Direito Processual, ano 11, vol 18, n.2, 2017, pp.261-296.

${ }^{16}$ ZANETTI, Hermes, O Novo Processo Civil Brasileiro e a Constituição. O Modelo Constitucional da Justiça Brasileira e o Código de Processo Civil de 2015, Salvador:JusPodivum, 2016, p.45.

${ }^{17}$ GRECCO, Leonardo Garantias Fundamentais do Processo: o Processo Justo. Novos Estudos Jurídicos - Ano VII $\mathrm{N}^{\circ} 14$ - p. 9-68, abril .2002, p.11.

${ }^{18}$ HILL, Flávia e PINHO, Humberto D.B., “A Nova Fronteira do Acesso à Justiça: A Jurisdição Transnacional e os Instrumentos de Cooperação Internacional no CPC/2015 Revista Eletrônica de Direito Processual, ano 11, vol 18, n.2, 2017, p. 265.

${ }^{19}$ JEVEAUX, Geovany C. Org. Uma Teoria da Justiça para o Acesso à Justiça, Rio de Janeiro:2012, p.5.

${ }^{20}$ HILL, Flávia e PINHO, Humberto D.B., op cit. p. 274.
}

Revista de Direito Brasileira | São Paulo, SP | v. 19 | n. 8 | p. 155 - 169 |Jan./Abr. 2018 


\section{LOS ANDAMIOS DE LA INMUNIDADES DE JURISDICCIÓN:LÍMITES Y POSIBILIDADES}

La Inmunidad de Jurisdicción del Estado se diferencia de las llamadas inmunidades Diplomáticas y Consulares. Estas últimas corresponden a beneficios y privilegios elaborados y solidificados a través de un largo proceso de armonización del derecho internacional, desembocada en dos convenciones multilaterales,concretamente, una primera sobre Relaciones Diplomáticas, incorporada al sistema nacional brasileño, a travésdel Decreto $\mathrm{n}^{\circ} 56.435$ en 08/06/1965 ${ }^{21}$ y otra sobre Relaciones Consulares, promulgada por el Decreto $\mathrm{n}^{\circ}$ 61.078en $26 / 07 / 1967^{22}$.

Tales inmunidades,se refieren a determinadas prerrogativas concedidas a las representaciones diplomáticas y consulares del Estado extranjero, en territorio de otro Estado nacional, con el fin de garantizar la independencia y estabilidad de sus agentes en el ejercicio de sus funciones, garantizándoles cierto grado de autonomía y una protección general en la ejecución de las políticas e intereses externos de sus Estados de origen. ${ }^{23}$

Por su parte, la inmunidad de jurisdicción del Estadono indica un conjunto de beneficios funcionales, de representación o de legación de los órganos estatales, sino al impedimento, en virtud del principio de igualdad soberana entre Estados, de que una autoridad judicial nacional procese un Estado extranjero,que por ventura tenga cometido un acto contrario al derecho internacional vigente en su territorio.

Estaprerrogativa, formuladacon un carácter absoluto ${ }^{24}$, como así también era la percepción de la soberanía nacional, pierde esta caracterización,con el proceso de mitigación de la soberanía del Estado a luz de los intereses de protección y promoción de los derechos humanos, y con el crecimiento de la necesidad de efectivizar el acceso a la justicia con el objetivo de asegurar la seguridadjurídica y la protección de personas y derechos.

\subsection{Mitigación de la Inmunidad de Jurisdicción en Brasil a la luz de la Convención de Las Naciones Unidas de 2004}

La búsqueda por la armonización de los sistemas jurídicos internacionales introduce desafíos en el sentido de establecer una relación de identidad entre los Estados. La actual

$21 \quad$ DOFC $\quad 11 \quad 06 \quad 1965 \quad 005539 \quad 2 \quad$ RET. 7/7/1965. Disponible en: 〈http://www.planalto.gov.br/ccivil_03/decreto/antigos/d56435.htm> Acceso al 17 jun. 2018.

${ }^{22}$ DOFC 28071967007946 2, disponible en: <http://www.planalto.gov.br/ccivil 03/decreto/d61078.htm> Acceso al 18 jun. 2018.

${ }^{23}$ La profesora Carmen Tibúrcio tales inmunidades se justifican en base a las teorías de la extraterritorialidad, que partía de la premisa de que la misión del Estado extranjero en el foro representaba territorio extranjero; la de representación, en esta existe la percepción de que el embajador y el cónsul extranjero personifican el Estado extranjero en el foro; y la funcional, que centraliza su justificativa en base a la protección por el derecho internacional de las funciones a ser desempeñadas por los representantes del Estado extranjero en el foro. Tibúrcio, Carmen, Extensão e Limites da Jurisdição Brasileira, Competência Internacional e Imunidade de Jurisdição, Ed Jus Podium, Salvador, 2016, p.378.

${ }^{24}$ El profesor Guido Soares llamaba la atención sobre la percepción de ser la inmunidad de jurisdicción, en rigor, un fenómeno reciente en el Derecho Internacional en lo que se refiere a su invocación constante ante los tribunales de los Estados, no siendo tan reciente algunas de sus manifestaciones, como las relativas a las inmunidades de los diplomáticos y del personal en las oficinas consulares. La emergencia del tema, continúa el autor, debe ser acreditada a por lo menos dos fenómenos: "la frecuencia de la práctica de determinados actos por el propio Estado que, en épocas anteriores, se había abstenido de realizar" y la "superación del principio de la administración pública por ser un órgano del Estado, que no podía someterse a la jurisdicción de los tribunales de su propio Estado de que no a de su propio Estado"( theking can do notwrong).SOARES F.S., Guido, As Imunidades de JurisdiçãonaJustiçaTrabalhista $\quad$ Brasileira. p. 520 e 521. Disponible en: <www.revistas.usp.br/rfdusp/article/download/67235/69845>Acceso al 16 jun. 2018. 
dinámica del escenario de la aldea global conduce a la reflexión sobre la necesidad de construir, en el plano internacional, relaciones de confianza, pautadas en la incorporación, por las naciones, de valores fundamentales comunes, capaces de orientar el ejercicio de la solidaridad en las interacciones transfronterizas.

Como anteriormente mencionado, la inmunidad de jurisdicción de Estados no contempla una reglamentación convencional de carácter multilateral en vigor. No obstante el consenso logrado por la "Convención de las Naciones Unidas de 2004 sobre la Inmunidad de Estados y sus bienes ${ }^{25}$ ", elaborada por la Comisión de Derecho Internacional de las Naciones Unidas con más de 25 años de negociaciones internacionales ${ }^{26}$, la ausencia del número mínimo de ratificaciones hace con que tal instrumento codificador aún no esté vigente internacionalmente ${ }^{27}$.

La Convención de 2004 representa un primer instrumento de naturaleza multilateral del derecho internacional moderno, que articula las cuestiones practicas originarias de los diversos casos judiciales sobre la materia al redor del globo ${ }^{28}$. Se consubstancia en 33 artículos representativos de la codificación de los principios y costumbres para una sustantiva armonización jurídica.

También en las esferas estatales, son escasos los ejemplos de legislaciones internas sobre la temática ${ }^{29}$, como es el caso de Brasil. La ausencia de reglas multilaterales y la escasez de normas nacionales generan inconsistencias y discrepancias en la aplicación de la inmunidad de jurisdicción por los sistemas judiciales nacionales. Y como telón de fondo está "la guerra de brazo" entre, por un lado, el mantenimiento de las prerrogativas inherentes a los Estados nacionales y sus intereses en la esfera internacional, en virtud del principio de igualdad soberana $\mathrm{y}$, por otro, el derecho fundamental al acceso a la justicia de los particulares, personas físicas o jurídicas, en la búsqueda de reparaciones por eventuales daños sufridos.

Utilizando como telón de fondo la Convención de las Naciones Unidas sobre Inmunidad de Estados y de sus Bienes, de 02 de diciembre de 2004, que cuenta con 22 ratificaciones, faltando 8 para su entrada en vigor, incluida la brasileña. Interesa apuntar un conjunto de materias en las que la inmunidad de jurisdicción se ve mitigada, frente a la necesidad de la promoción del acceso a la justicia vis à vis la práctica nacional.

Hasta la década de ochenta los tribunales brasileros reconocían los privilegios de la inmunidad de jurisdicción y de la inmunidad de ejecución como absolutas. A partir de 1989, con la decisión en la Apelación Civil 9696-3 Genny de Oliveira v. RDA, el Supremo Tribunal Federal modifica su jurisprudencia, consagrando la inmunidad de jurisdicción relativa e invocando como justificativa las legislaciones más avanzadas en ese momento (Convención Europea de Basilea de 1972 así como las leyes británica y americana ${ }^{30}$ ). Fue, así, en la búsqueda

\footnotetext{
${ }^{25}$ La Convención de las Naciones Unidas sobre Inmunidad de Jurisdicción de Estados y de sus Bienes, adoptada em la 65 sesión plenaria de la Asamblea General de las Naciones Unidas, Resolución A/59/38, de 02/12/ 2004.

${ }^{26}$ Sobre histórico de la Convención vid. David P. Stewart, The Immunity of State Officials under the UN Convention on Jurisdictional Immunities of States and Their Property, VANDERBIL JOURNAL OF TRANSNATIONAL LAW, vol.44/1047, 2011, p.1050.

${ }^{27}$ Actualmente la Convención de las Naciones Unidas sobre Inmunidad de Jurisdicción de Estados y de sus Bienes posé 28 asignaturas y 22 ratificaciones, restando 8 ratificaciones para su entrada en vigor. Disponible en: <https://treaties.un.org/Pages/ViewDetails.aspx?src=TREATY\&mtdsg_no=III-13\&chapter=3\&clang= en.>Acceso al 16 jun. 2018.

${ }^{28}$ DAVID P. Stewart, The Immunity of State Officials under the UN Convention on Jurisdictional Immunities of States and Their Property, VANDERBIL JOURNAL OF TRANSNATIONAL LAW, vol.44/1047, 2011, p.1050.

${ }^{29}$ En el ámbito regional, la reglamentación de la inmunidad de jurisdicción de Estado encuentra un eco en la normativa europea sobre la temática, vigente desde 1972, a "EuropeanConventionStateImmunity". Disponible en: $<$ https://rm.coe.int/16800730b1 > Acceso al 16 jun. 2018.

30 JIMENEZ, Martha L O e MOSCHEN, Valesca R.B., Las inmunidades de Estado Extranjero en la Pauta del Judiciário Brasileño: Avances y Desafios, Civil ProcedureReview, v.4, n.3: 99-121, sep-dec., 2013 ISSN $2191-1339$ - www.civilprocedurereview.com. p. 111.
}

Revista de Direito Brasileira | São Paulo, SP | v. 19 | n. 8 | p. 155 - 169 |Jan./Abr. 2018 
de la protección de los derechos de los trabajadores que la inmunidad de jurisdicción del Estado se flexibilizó en materia laboralen Brasil.

Desde 1988, por advenimiento de la Constitución Ciudadana, que se entiende que en las relaciones de trabajo entre nacionales (residentes en Brasil) y los Estados extranjeros (ya sean sus representaciones directas o indirectas, embajadas, consulados, agencias de cooperación comercial, y otros) prevalece la ley y la jurisdicción brasileña ${ }^{31}$.

Por su vez, la Convención de las Naciones Unidas de 2004, afirma que un Estado no puede invocar la inmunidad jurisdiccional ante un tribunal de otro Estado que sea competente para juzgar el caso, en un procedimiento judicial que se refiera a un contrato de trabajo entre el Estado y una persona física, para un trabajo realizado o que se debía realizar, en todo o en parte, en el territorio de ese otro Estado ${ }^{32}$.Sin embrago, la mitigación de la inmunidad de jurisdicción en materia laboral no es absoluta, sus límites se relacionan especialmente a la naturaleza de la función ejercida por el trabajador.

La normativa internacional, afirma un conjunto de excepciones a la exclusión de la inmunidad, a saber: a) el trabajador tenga sido contratado para desempeñar funciones específicas que se derivan del ejercicio de poderes públicos; b) cuando goce de inmunidad diplomática conforme a los Convenciones de Viena de 1961 y de 1963; c) cuando el procedimiento judicial se refiera al cese unilateral del contrato o al despido del trabajador y, si así lo determina el jefe de Estado,el jefe de gobierno o el ministro de asuntos exteriores del Estado de empleador, dicho procedimiento cuestiona los intereses de seguridad de dicho Estado; d) en caso de que el trabajador nacional del Estado empleador en el momento de la incoación del procedimiento judicial, a menos que el interesado tenga residencia permanente en el Estado del foro; o f) si el Estado y el trabajador acordaron por escrito, la reserva de consideraciones de orden público que conferían a los tribunales del Estado de jurisdicción exclusiva en función del objeto del proceso $^{33}$.

Las decisiones judiciales nacionales han generado un entendimiento en favor de la mitigación de la inmunidad de jurisdicción, siguiendo la Convención, no por la interpretación de la actuación del Estado en sí, sino, por la propia necesidad de protección de los derechos laborales cuando en la relación estéausente una función pública de naturaleza política. La comprensión de la Inmunidad de Estado, relativizando la idea abstracta de protección Estatal basada en el principio de la soberanía y buscando, la promoción de la garantía de efectividad de derechos a los particulares involucrados en una relación jurídica concreta es una realidad en el sistema brasileño en materia laboral.

En el ámbito civil y comercial, de conformidad con el artículo décimo de la Convención de las Naciones Unidas de 2004, si un Estado realiza una transacción comercial con una persona física o colectiva extranjera $\mathrm{y}$, como consecuencia de las normas aplicables de Derecho internacional privado, las divergencias relativas a dicha transacción comercial se someten a la jurisdicción de un Estado tribunal de otro Estado, el Estado no puede invocar inmunidad de jurisdicción en un proceso judicial relativo a la misma transacción comercial ${ }^{34}$.

En el caso brasileño, se han observado los parámetros citados en cuanto al límite al ejercicio de la inmunidad de jurisdicción en temas comerciales, como en los contratos

\footnotetext{
${ }^{31}$ Con la nueva redacción del artículo 114 de la Constitución Federal Brasileña, fruto de la reforma constitucional lograda por la Enmienda Constitucional n.45/2004 , es clara la jurisdicción de la Justicia Laboral brasileña en procesar y juzgar: "i. as ações oriundas das relações de trabalho, abrangendo entes de direito público externo...". Disponible en: 〈http://www.senado.leg.br/atividade/const/con1988/con1988_18.02.2016/art_114_asp〉 Acceso al 15 jun. 2018.

${ }^{32}$ Artículo 11 de la Convención de 2004.

${ }^{33}$ Inciso 2 del artículo 11 de la Convención.

${ }^{34}$ Esta limitación contempla algunas excepciones previstas en la propia Convención, a saber: a) en el caso de una transacción comercial entre Estados; b) Si las partes en la transacción comercial han acordado expresamente en sentido distinto. Conforme artículo $10^{\circ}$, inciso 2 de la Convención de 2004.
} 
empresariales, así el Estado extranjero podría ser accionado en al país ${ }^{35}$. Un ejemplo relativamente reciente es el del Recurso Ordinario contra los Estados Unidos Mexicanos, STJ RO $\mathrm{n}^{\circ} 26$ / RJ (2003-0049144-3) ${ }^{36}$, en cuya sentencia se confirma el posicionamiento nacional en los moldes del proclamado por la Convención de las Naciones Unidas de 2004,

"En el caso de que el objeto litigioso tenga como fondo relaciones de naturaleza meramente laborista, comercial o civil, como ocurre en la hipótesis de los autos, en el caso de autos, donde no se ha de hablar más en inmunidad absoluta de jurisdicción, que pretende el autor de la demanda es obtener la reparación civil por el supuesto incumplimiento de contrato verbal celebrado con el demandado para la elaboración de proyecto para realización de exposición que se realizaría en Río de Janeiro, bajo la denominación de "EXPO MÉXICO - SÉCULO XXI".

En Brasil, no obstante, la mitigación d la inmunidad en temas laborales y comerciales, el enfrentamiento entre la inmunidad de jurisdicción y la violación de derechos humanos viene siendo de difícil solución. Si en los temas de relaciones laborales y empresariales ya se observa una convergencia del entendimiento nacional y del instrumento internacional armonizador, en temas de daños ocasionados a personas y sus bienes por el Estado extranjero, la solución brasileña no se asemeja a la propuesta por la Convención de 2004.

“La particularidad de la solución brasileña está en la ausencia de análisis o de mención al objetivo perseguido por esos dispositivos normativos: acabar con la discrecionalidad de los jueces sobre la naturaleza del acto y en consecuencia sobre la concesión o no del privilegio de la inmunidad al Estado extranjero $^{37,}$

De esta forma, su construcción jurisprudencial nacional contraria a los parámetros de la Convención, en la medida en que sigue determinando, a partir de la lente de la soberanía nacional y no por los objetivos perseguidos por la normativa, la mitigación o no de la inmunidad de jurisdicción de Estados extranjeros por actos que ocasionaron daños a particulares en su país territorio. Algunos ejemplos elucidan el tema:

\footnotetext{
${ }^{35}$ Carmen Tiburcio afirma que después de la flexibilización en materia laboral por el Supremo Tribunal Federal de Brasil, se decidió por la relativización de la inmunidad en materia comercial. Vid. TIBURCIO, Carmen, Extensão e limites da jurisdição brasileira: competência internacional e imunidade de jurisdição. Salvador:Jus PODIVUM, 2016, p.309.

${ }^{36}$ Decisión del STJ, disponible en: <http://stj.jusbrasil.com.br/jurisprudencia/14331092/recurso-ordinario-ro-26-rj2003-0049144-3/inteiro-teor-14331093> Acceso al 17 jun. 2018. Otro ejemplo, aunque no de carácter esencialmente comercial, fue el de la acción ordinaria propuesta por un ciudadano brasileño contra Estados Unidos de América, EE.UU., alegando constituirse en acreedor de la promesa de recompensa públicamente efectuada por el Estado recurrente, equivalente a (25.000 millones de dólares, ya que, con el don de la premonición, habría indicado el escondite del ex dictador iraquí Saddam Hussein, capturado a los 14.12.2003.) Disponible en: <Http: // http: stj.jusbrasil.com.br/jurisprudencia/54861/recurso-ordinario-ro-39-mg-2004-0088522-2> Acceso al 18 jun. 2018. Primeramente la acción fue extinguida, sin juicio del mérito, por alegación de incompetencia de la justicia brasileña, decisión reformada a través del Recurso Ordinario 39 / MG, en el cual se reconoció la competencia concurrente de la autoridad judicial brasileña, en los términos del art.88, III , del CPC ( anterior Código Procesal) y, simultáneamente, las inmunidades de jurisdicción y ejecución al Estado extranjero por entendimiento de que "la manifestación unilateral de voluntad no evidenció carácter meramente comercial o expresó relación rutinaria entre el Estado promitente y los ciudadanos brasileños, consubstanciando, al revés, expresión de soberanía estatal, revistándose de oficialidad, siendo motivada, de forma atípica, por la deflagración de guerra entre el Estado ofertante (USA) y la Nación diversa (Iraque), luego no excluyendo el recurso a la inmunidad de jurisdicción por el Estado Extranjero.

37 JIMENEZ, Martha L O e MOSCHEN, Valesca R.B., Las inmunidades de Estado Extranjero en la Pauta del Judiciário Brasileño: Avances y Desafios, Civil ProcedureReview, v.4, n.3: 99-121, sep-dec., 2013 ISSN 2191-1339 - www.civilprocedurereview.com.
}

Revista de Direito Brasileira | São Paulo, SP | v. 19 | n. 8 | p. 155 - 169 |Jan./Abr. 2018 
a) (RO60 / RJ 2007 / 0279903-8) - En la Decisión STJ de 19/02/2016, se reconoció la inmunidad del Estado alemán en una acción de indemnización por daños causados por actos practicados en el territorio nacional, relativo al hundimiento de un barco pesquero (Changrilá), en aguas brasileñas, en el litoral de Cabo Frío-RJ, por un submarino alemán (U-199), en julio de 1943. Recientemente, el Supremo Tribunal Federal (STF) reconoció la existencia de repercusión general sobre la temática concerniente al alcance de la inmunidad de jurisdicción de Estado extranjero en relación a actos de imperio practicados durante la Segunda Guerra, según la decisión que sigue:

RECURSO EXTRAORDINÁRIO COM AGRAVO. REPERCUSSÃO GERAL. DIREITOS HUMANOS. DIREITO INTERNACIONAL. ESTADO SOBERANO ESTRANGEIRO. IMUNIDADE DE JURISDIÇÃO. PROCESSO DE CONHECIMENTO. COMPETÊNCIA. ATOS DE IMPÉRIO. ATOS DE GESTÃO. DELITO CONTRA O DIREITO INTERNACIONAL DA PESSOA HUMANO. PERÍODO DE GUERRA. DIREITOS DE PERSONALIDADE. SUCESSORES DA VÍTIMA. INDENIZAÇÃO. 1. O alcance da imunidade de jurisdição de Estado estrangeiro em relação a ato de império ofensivo ao direito internacional da pessoa humana é tema constitucional digno de submissão à sistemática da repercussão geral. 2. A controvérsia consiste em definir a viabilidade de processamento e julgamento de lide que envolve Estado soberano estrangeiro por parte do Poder Judiciário brasileiro. 3. Preliminar de repercussão geral reconhecida.

(ARE 954858 RG, Relator(a): Min. EDSON FACHIN, julgado em 11/05/2017, PROCESSO ELETRÔNICO DJe-108 DIVULG 23-05-2017 PUBLIC 24-05-2017) $)^{38}$

b) $\left(\right.$ RO57 / RJ 2009) ${ }^{39}$ - La familia del ex mandatario João Goulartinició una acción contra Estados Unidos de América exigiendo su condena por daños morales y materiales, en virtud de la participación de autoridades norteamericanas en su deposición. La inmunidad no fue alejada, incluso tratándose de acto ilícito ocurrido en el territorio brasileño, tal como proclama la Convención de $2004^{40}$.

c) (RO83 / DF 2009) No hubo la desconsideración de la inmunidad de jurisdicción del Estado Holandés por haber facilitado la fuga de criminales de su ciudadanía, procesados en el Estado Brasileño por explotación sexual de menores, que después de ser puestos en libertad en presencia de un representante consular, con sus pasaportes debidamente aprehendidos, y en la estricta condición de que no se ausentaban del distrito de la culpa sin autorización judicial, huyeron del país utilizando pasaportes emitidos por el consulado holandés de naturaleza de emergencia.

En este particular, la firma y ratificación de Brasil de la Convención de las Naciones Unidas sobre Inmunidad de Jurisdicción de Estados y sus Bienes, aún no ocurrida, permitiría una

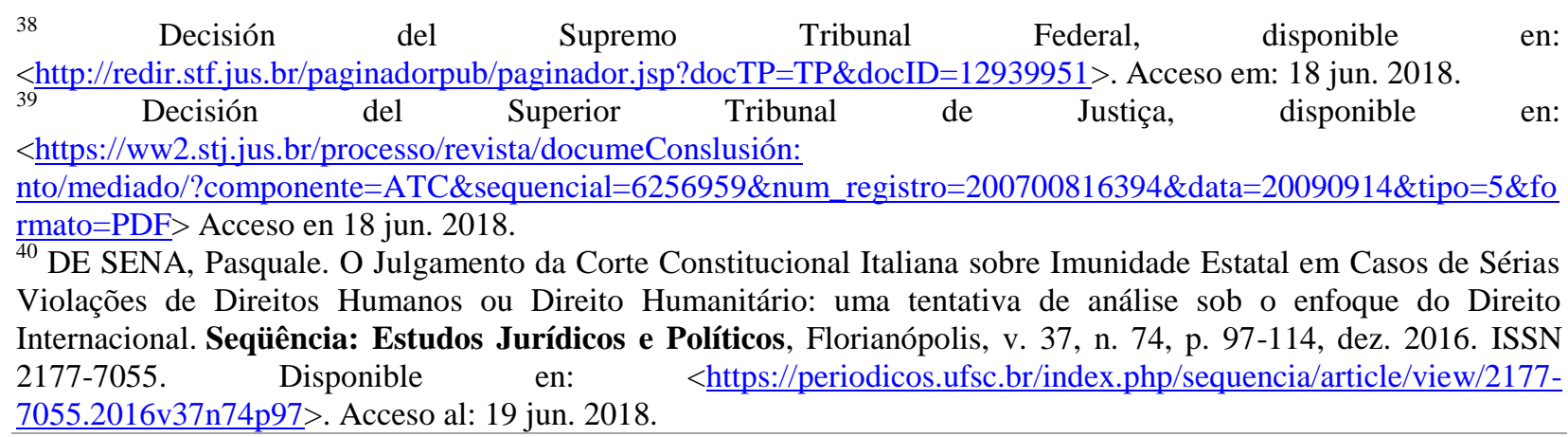


mejor comprensión y aplicación del instituto por la justicia nacional y fomentaría el cambio necesario de interpretación en favor de la protección y la promoción de los derechos humanos a escala mundial.

\section{CONSIDERACIONES FINALES: LA DICTADURA BRASILEÑA EN LOS TRIBUNALES ITALIANOS ¿NUEVA DIMENSIÓN DE LA INMUNIDAD?}

La mayor interacción con el sistema de derecho internacional público a raíz de la consagración y expansión de los derechos humanos, yla emergencia de los temas de jurisdicción y cooperación jurídica internacional como instrumentos de la concreción de la justicia, contribuye a la consolidación de la solidaridad y la cooperación internacional interestatal ${ }^{41}$.

En este sentido, lapropuesta de Convención de 2004, tal como ya mencionado, se destina a la consolidación de los principios y costumbres consagrados por la practica enconflictos entre un particular y un Estado extranjero en foro diferente del estatal. Este instrumento multilateral es claro al determinar que los daños ocasionados a personas y/o sus bienes por actos ilícitos practicados por un Estado en el foro de otro, configura una excepción a la inmunidad de jurisdicción.

De esta forma, en termos de la violación de derecho humanos ocurridos en el territorio distinto del estado responsable por la violación, la inmunidad de jurisdicción no encuentra garita en las normas convencionales.

No obstante la existencia de la obligación convencional de mitigación de la inmunidad, basada en la práctica y en los valores fundamentales de protección y promoción de los derecho humanos de la comunidad internacional, algunos estados nacionales, entre los cuales el brasileño,aún orientan sus deliberaciones en la relación de la inmunidad de jurisdicción y la naturaleza de los actos estatales, se imperio o gestión, método, aunque suficiente para una análisis general, no representa en la actualidad el mejor derecho aplicable a la materia de violaciones de derechos humanos ${ }^{42}$.

Como mencionado, la Convención estipula la flexibilización de la inmunidad, en los daños ocasionados por un Estado extranjero en territorio de otro Estado. De otro lado, en términos de la violación de derechos fundamentales ocurridos fuera del territorio del foro, la cuestiona que se impone es la de saber si existe la extensión y prevalencia del beneficio de la inmunidad de jurisdicción ${ }^{43}$, o si en esto casos, también, a raíz de la protección primordial de los derechos fundamentales debe ser mitigada la inmunidad.

Una oportunidad para el análisis de la dualidad entre el acceso a la justicia de las víctimas de derechos humanos versus la inmunidad de jurisdicción del Estado agresor, es el reciente caso en curso en la $1{ }^{\mathrm{a}}$ Corte Penal del Tribunal de Roma, que juzga el desaparecimiento de Lorenzo Ismael Viñas, supuesta víctima de la operación cóndor, alianza político-militar, entre gobiernos dictatoriales de América del Sur, especialmente, Brasil, Argentina, Uruguay, Paraguay, Chile y Bolivia, constituida con anuencia norteamericana, para la coordinación de la represión en los años 60, 70 y $80^{44}$.

Lorenzo Ismael Viñas era estudiante de Ciencias Sociales en Buenos Aires, presunto miembro del movimiento guerillero "Montoneros", exilado en Méjico desde 1976, vuele a Argentina entre 1979 y 1980, y desaparece en el 26/06/1980 en la frontera brasileña con

\footnotetext{
${ }^{41}$ Para Haberle el Estado Constitucional Cooperativo es la respuesta interna del Estado Constitucional occidental libre y democrático al cambio en el Derecho Internacional. Para él el Estado Constitucional y el Derecho Internacional se transforman en conjunto. HABERLE, Peter, op.cit., P.10 y 11

${ }^{42}$ Ministro Luis Felipe Salomão, voto enRecurso Extraordinário nº0 - RJ (2007/0279903-8), STJ Documento 915231, site certificado, Dje 19/02/2016, p.11.

43 TIBURCIO, Carmen, Extensão e limites da jurisdição brasileira: competência internacional e imunidade de jurisdição, op. cit., p.315.

${ }^{44}$ PAREDES, Alejandro. La Operación Cóndor y la guerra fria. Revista Universu no ${ }^{\circ}$ 19 Vol.1:122-137, 2004.
}

Revista de Direito Brasileira | São Paulo, SP | v. 19 | n. 8 | p. 155 - 169 |Jan./Abr. 2018 
Argentina, enUruguayana,a camino de Rio de Janeiro, donde embarcaría para un nuevo exilio en dirección altalia, país de residencia de sus padres ${ }^{45}$.

Un total de 33 personas fueron denunciadas por el ministerio publico italiano acusadas de participaren de un conjunto de crimines contra la humanidad, como los de desaparición forzadas, tortura y asesinato, impetrados en el periodo e vigencia de la operación cóndor. Entre los acusados están cuatro brasileños, el secretario de Seguridad de Rio Grande do Sulde la época; el director de la agencia del SNI (Servicio Nacional de Informaciones) en Porto Alegre; el director de la División Central de Informaciones de Rio Grande do Sul; y delegado de policía, cubría el cargo de director del Dops (Departamentos de Orden Político y Social) de Rio Grande do Sul.

La eventual condenade agentes de la represión brasileña por la justicia italiana podrá representar un nuevo rumbo en el ámbito de la inmunidad de jurisdicción estatal en favor de los derechos humanos y servir como una vía de acceso a la justicia, para victimas que no vislumbran la efectividad de derechos en el judiciario brasileño, una vez que, por mayoría de votos, el Supremo Tribunal Federal, en la ADPF n¹53, decidió por la recepción de la "Lei de Anistia", Ley $n^{\circ} 6.683 / 79$, en la Constitución Federal Brasileña y la consecuente imposibilitando la investigación y condena de los responsables por los crimines ocurridos durante el periodo militar en Brasil.

Tal decisión, contraría los ejemplos de la protección y promoción de derechos fundamentales y del justo e efectivo acceso a la justicia y "no presenció el proceso de internacionalización del Derecho y la evolución del Estado-acción para el Estado Constitucional Cooperativo, dentro de la Teoría de la Democracia ${ }^{46,}$.

\section{CONCLUSIÓN}

Los nuevos paradigmas de Estado constitucional cooperativo y del propio proceso de transformación del derecho internacional público, privado y procesal, llevan al redimensionamiento de la comprensión, interpretación y aplicación de institutos jurídicos tradicionales como la inmunidad de jurisdicción.

Bajo la óptica de la mitigación de la soberanía estatal, el panorama mundial se propone asumir nuevas técnicas que visen la garantía y la eficacia de los derechos fundamentales de la persona humana en las diversas jurisdicciones existentes.Se pretende concretar la aproximación de valores y prácticas, en detrimento de los obstáculos al acceso a la justicia a menudo colocados por los Estados soberanos, y asegurar la seguridad para las relaciones jurídicas, especialmente entre particulares y un Estado.Para ello, se adoptan mecanismos cooperativos, con el objetivo de aproximar las jurisdicciones estatales, desde la perspectiva de armonización de los sistemas jurídicos ${ }^{47}$, como ejemplifica la Convención de las Naciones Unidas de 2004 sobre Inmunidad de Estados y de sus Bienes.

El auge de los derechos humanos de dimensión internacional, insertos en el contexto de los Estados constitucionales, propicia la preconización del acceso a la justicia como principio fundamental y el consecuente reconocimiento de la obligación de los Estados cooperar jurídicamente entre sí con el alcance de realización y de protección de los derechos humanos en particular, del derecho de acceso a la justicia.

\footnotetext{
${ }^{45}$ Conforme el expediente descriptivo de Lorenzo Ismael Viñas contenido en la Comisión Especial sobre Muertos y Desaparecidos en Brasil. Disponible en: 〈http://cemdp.sdh.gov.br/modules/desaparecidos/acervo/ficha/cid/181.> Acceso al 18 jun. 2018.

${ }^{46}$ SILVEIRA, V. O.; Meyer-PFLUG, S. R... A Decisão do STF na ADPF 153 (Lei de Anistia). Revista de Direito Brasileira, v. 3, 2012. p. 451-462.

${ }^{47}$ MOSCHEN, Valesca Raizer Borges. CAMPEÃO, Paula Soares. A Cooperação Jurídica Internacional na Harmonização do Direito Internacional Privado e o Código de Processo Civil Brasileiro. Revista dos Tribunais. Caderno Especial- Cooperação Jurídica Internacional. Vol. 1.Abr/2018. pp. 17-35.
}

Revista de Direito Brasileira | São Paulo, SP | v. 19 | n. 8 | p. 155 - 169 |Jan./Abr. 2018 
A pesar de ser un concepto vinculado al principio de la soberanía estatal, el hecho es que la inmunidad de jurisdicción presenta repercusiones en el ámbito de la efectividad de derecho y garantías fundamentales. La aplicación de tal instituto sin observar los verdaderos objetivos existentes en la práctica y en la normativa convencional, conlleva en muchos casos, como los de violación de derechos fundamentales, a una verdadera denegación de la justicia.

En este sentido, la perspectiva en boga presupone la mitigación del tradicional concepto de inmunidad de jurisdicción, a fin de comprenderla bajo una dimensión más amplia, caracterizada por la canalización de la práctica de actos procesales entre diferentes Estados, propiciando el efectivo acceso a la justicia.De esta forma, se propone promover y garantizar la estabilidad del fenómeno jurídico multifacético, a través de la unidad valorativa entre los diversos sistemas procesales interesados, adecuando sus métodos procesales al conjunto de principios de derechos fundamentales.

\section{REFERENCIAS}

ARAÚJO, Nadia de. Direito Internacional Privado. Teoria e Prática Brasileira. $1^{\mathrm{a}}$ ed. Porto Alegre: RevoluçãoeBook, 2016.

BONET, Jordi Perez, La Inmunidad de Jjurisdicción del Estado en la Jurisprudencia del Tribunal Europeo de Derechos Humanos: la relación laboral al servicio de oficinas diplomáticas. FORNER, Delaygua, Joaquim, BEILFUSS, Cristina Gonzales y VIÑAS, RamóinFarré (coord.) Entre Bruselas y la Haya Estudios sobre la unificación inter acional y regional del Derecho internacional privado, LiberAmicorum Alegría Borras, Barcelona; marcial Pons, 2013, p.225239. Esp. 235.

CAPPELLETTI, Mauro (ed) Access to Justice and the Welfare State. Forenze: BadiaFiesola, 1981.

DAVID P. Stewart, The Immunity of State Officials under the UN Convention on Jurisdictional Immunities of States and Their Property, VANDERBIL JOURNAL OF TRANSNATIONAL LAW, vol.44/1047, 2011.

DE SENA, Pasquale. O Julgamento da Corte Constitucional Italiana sobre Imunidade Estatal em Casos de Sérias Violações de Direitos Humanos ou Direito Humanitário: uma tentativa de análise sob o enfoque do Direito Internacional. Seqüiência: Estudos Jurídicos e Políticos, Florianópolis, v. 37, n. 74, p. 97-114, dez. 2016. ISSN 2177-7055. Disponible en: <https://periodicos.ufsc.br/index.php/sequencia/article/view/2177-7055.2016v37n74p97>.

Acceso al: 19 jun. 2018.

DIAS, Maria Tereza Fonseca; GUSTIN, Miracy Barbosa de Sousa. (Re)Pensando a pesquisa jurídica: teoria e prática. 4. ed. Belo Horizonte: Del Rey, 2013.

DIDIER, Fredie Jr, Curso de Direito Processual Civil, 17 ed., Salvador:Ed Jus Podivm, 2015.

DOFC $1106 \quad 19650055392$ RET. 7/7/1965. Disponible en: <http://www.planalto.gov.br/ccivil_03/decreto/antigos/d56435.htm> Acceso al 17 jun. 2018.

DOFC $28 \quad 07 \quad 1967 \quad 007946 \quad 2, \quad$ disponible <http://www.planalto.gov.br/ccivil_03/decreto/d61078.htm> Acceso al 18 jun. 2018. 
DOLINGER, Jacob; TIBURCIO, Carmen. Direito Internacional Privado. 13. ed. Rio de Janeiro: Forense, 2017.

FINKE, Jasper Sovereign Immunity: Rule. Comity or Something else? European Journal of International Law, Vol.21, n.4, 853-881,esp.

GRECCO, Leonardo Garantias Fundamentais do Processo: o Processo Justo. Novos Estudos Jurídicos - Ano VII - No 14 - p. 9-68, abril .2002.

HABERLE, Peter. Estado constitucional cooperativo. Rio de Janeiro: Renovar, 2007.

HILL, Flávia e PINHO, Humberto D.B., “A Nova Fronteira do Acesso à Justiça: A Jurisdição Transnacional e os Instrumentos de Cooperação Internacional no CPC/2015 Revista Eletrônica de Direito Processual, ano 11, vol 18, n.2, 2017.

JEVEAUX, Geovany C. Org. Uma Teoria da Justiça para o Acesso à Justiça, Rio de Janeiro: 2012.

JIMENEZ, Martha L O e MOSCHEN, Valesca R.B., Las inmunidades de Estado Extranjero en la Pauta del Judiciário Brasileño: Avances y Desafios, Civil ProcedureReview, v.4, n.3: 99-121,sepdec., 2013 ISSN 2191-1339. Disponible en: 〈www.civilprocedurereview.com> Acceso en 15 jun. 2018.

KERAMEUS, Konstantinos D. L’harmonisationpróceduraledans le monde contemporain. KLOR, Adriana Dreyzin de; ARROYO, Diego Fernandez; PIMENTEL, Luiz Otávio (Org.). Direito do comércio internacional: litígio judicial internacional, Florianópolis: Boiteux, 2005.

LOPES, Inez, A família transacional e a cooperação jurídica internacional. Revista dos Tribunais. Caderno Especial. Cooperação Jurídica Internacional. vol I, Abril/2018.

LUPOI, Michele Ângelo. Conflittitransnazionalidigiurisdizioni. Tomo I, Giuffré: Milano, 2002.

MADRUGA FILHO, Antenor, A renúncia à imunidade de jurisdição pelo estado brasileiro e o novo direito de imunidade de jurisdição. Rio de Janeiro:Renovar, 2003.

MOSCHEN, Valesca Raizer Borges. CAMPEÃO, Paula Soares. A Cooperação Jurídica Internacional na Harmonização do Direito Internacional Privado e o Código de Processo Civil Brasileiro. Revista dos Tribunais. Caderno Especial- Cooperação Jurídica Internacional. Vol. 1. pp. 17-35. Abr/2018.

PAREDES, Alejandro. La Operación Cóndor y la guerra fria. Revista Universu no 19 Vol.1:122$137,2004$.

RAMOS, André de Carvalho. Direito Internacional Privado e seus Aspectos Processuais: A Cooperação Jurídica Internacional. Direito Internacional Privado e a nova cooperação jurídica internacional/André de Carvalho Ramos e Wagner Menezes (organizadores). Belo Horizonte: Arraes Editores, 2015. 
RAMOS, André de Carvalho; MENEZES, Wagner (Org.). Direito Internacional Privado e a Nova Cooperação Jurídica Internacional. Belo Horizonte: Arraes Editores, 2014.

RAMOS, A. C.; Zaneti Júnior, Hermes; MOSCHEN, Valesca Raizer Borges . Temas controversos do Direito Processual Civil Internacional: A Cláusula de Eleição de Foro e os Limites do Exercício Jurisdicional na Convenção de Haia de 2005 e no Código de Processo Civil Brasileiro de 2015. In: André de Carvalho Ramos. (Org.). Direito Internacional Privado: Questões Controvertidas. 1. ed. Belo Horizonte: ARRAES, 2016.

SILVEIRA, V. O; CASTRALLI, R. B. . A dimensão ecológica dos direitos humanos e a redefinição do valor do trabalho humano. REVISTA THESIS JURIS, v. 04, 2015. pp. 61-86.

SILVEIRA, V. O.; Meyer-PFLUG, S. R... A Decisão do STF na ADPF 153 (Lei de Anistia). Revista de Direito Brasileira, v. 3, 2012.

SOARES F.S., Guido, As Imunidades de Jurisdição na Justiça Trabalhista Brasileira. p. 520 e 521. Disponible en: <www.revistas.usp.br/rfdusp/article/download/67235/69845>Acceso al 16 jun. 2018.

TIBÚRCIO, Carmen. Extensão e Limites da Jurisdição Brasileira, Competência Internacional e Imunidade de Jurisdição, Ed Jus Podium, Salvador, 2016.

WAMBIER, Tereza Arruda Alvim; JR. Fredie Didier; TALAMINI, Eduardo; DANTAS, Bruno. Breves Comentários ao Código de Processo Civil. São Paulo: Editora Revista dos Tribunais, 2015.

ZANETTI, Hermes, O Novo Processo Civil Brasileiro e a Constituição. O Modelo Constitucional da Justiça Brasileira e o Código de Processo Civil de 2015, Salvador:JusPodivum, 2016. 